$4^{\text {th }}$ International Meeting on Calcitonin Gene-Related Peptide (CGRP)

TheScientificWorld (2001) 1(S1), 41

ISSN 1532-2246; DOI 10.1100/tsw.2001.417

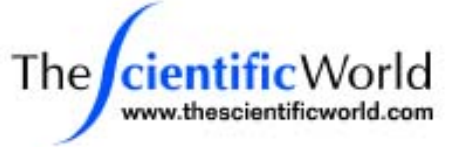

\title{
EXERCISE-INDUCED CALCITONIN GENE-RELATED PEPTIDE (CGRP) INCREASE DURING NORMOXIA AND HYPOXIA
}

\author{
P. Hasbak ${ }^{\mathrm{a}, \mathrm{b}, \mathrm{c}}$, C. Lundby ${ }^{\mathrm{d}}$, N.V. Olsen ${ }^{\mathrm{d}}$, S. Schifter ${ }^{\mathrm{b}}$, and I.L. Kanstrup ${ }^{\mathrm{a}}$ \\ ${ }^{\mathrm{a}}$ Department of Clinical Physiology and Nuclear Medicine, University Hospital of Herlev, Herlev; \\ ${ }^{b}$ Department of Clinical Physiology and Nuclear Medicine, University Hospital of Glostrup, \\ Glostrup; 'Department of Clinical Experimental Research, University Hospital of Glostrup, \\ Glostrup; ${ }^{\mathrm{d}}$ Department of Pharmacology, Panum Institute, University of Copenhagen, Denmark
}

To date calcitonin gene-related peptide (CGRP) is the most potent vasodilatatory peptide described. Evidence indicates that the level of CGRP increases during exercise in humans. Furthermore, hypoxia, lactic acid (LA) and sympathetic activity affect the release of CGRP. We therefore studied how CGRP levels would be influenced by maximal exercise in humans during normoxia, acute and prolonged hypoxia.

Twelve healthy volunteers were investigated at sea level (SL), day 1 (HA1) and day 5 (HA5) in high altitude (4559 m). CGRP, calcitonin (CT), noradrenalin (NA), adrenalin (A), LA, and heart rate $(\mathrm{HR})$ were measured at rest and during maximal exercise $\left(\mathrm{W}_{\max }\right)$ on a bicycle ergometer. At SL, HA1, and HA5, CGRP increased significantly from resting levels to $\mathrm{W}_{\max }$ along with NA, LA, HR, whereas A only increased significantly at sea-level and HA1. CT did not change at $\mathrm{W}_{\max }$. The CGRP levels at $\mathrm{W}_{\max }$ were significantly decreased at HA1 (74.3 \pm 6.1 pmol/l; $p=0.008)$ and HA5 (69.6 $\pm 6 ; p=0.003)$ compared to CGRP (80.9 $\pm 5.1 \mathrm{pmol} / \mathrm{l})$ at SL. This pattern was similar for LA and $\mathrm{HR}$ at $\mathrm{W}_{\max }$ during acute and prolonged hypoxia, whereas the NA and A responses were not. At rest neither acute nor prolonged hypoxia changed the CGRP, CT, or LA levels, whereas NA, A, and HR changed significantly compared to SL.

The exact signal for release of CGRP cannot be stated from this study, but we hypothesize that the release of CGRP and LA are correlated and that CGRP does not solely act as a counter regulatory mechanism to the sympathetic vasoconstrictor NA. 


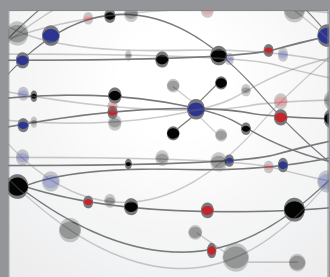

The Scientific World Journal
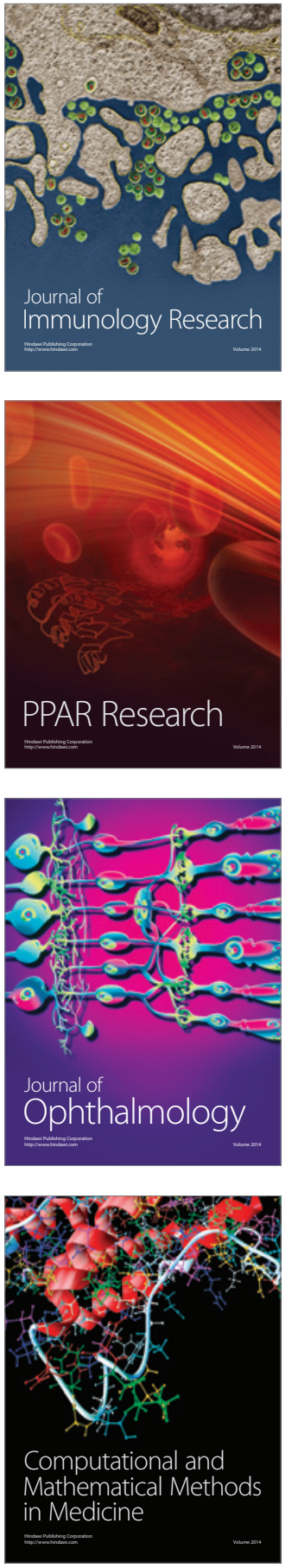

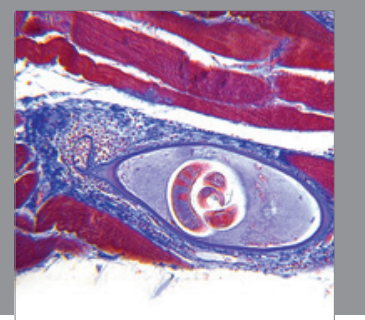

Gastroenterology

Research and Practice
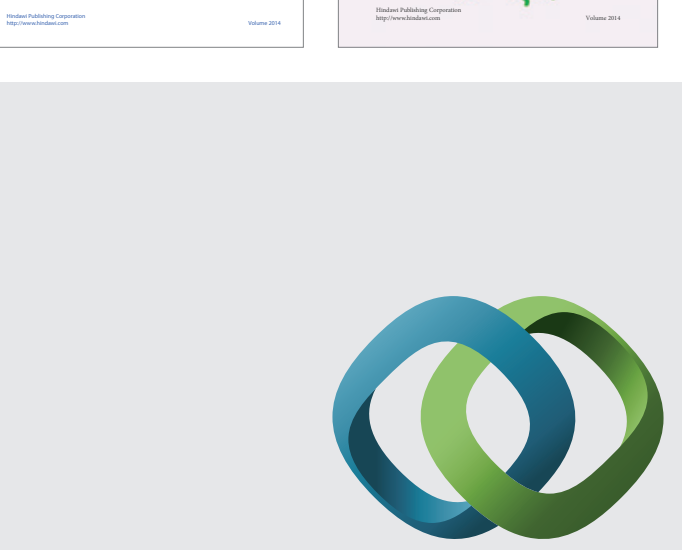

\section{Hindawi}

Submit your manuscripts at

http://www.hindawi.com
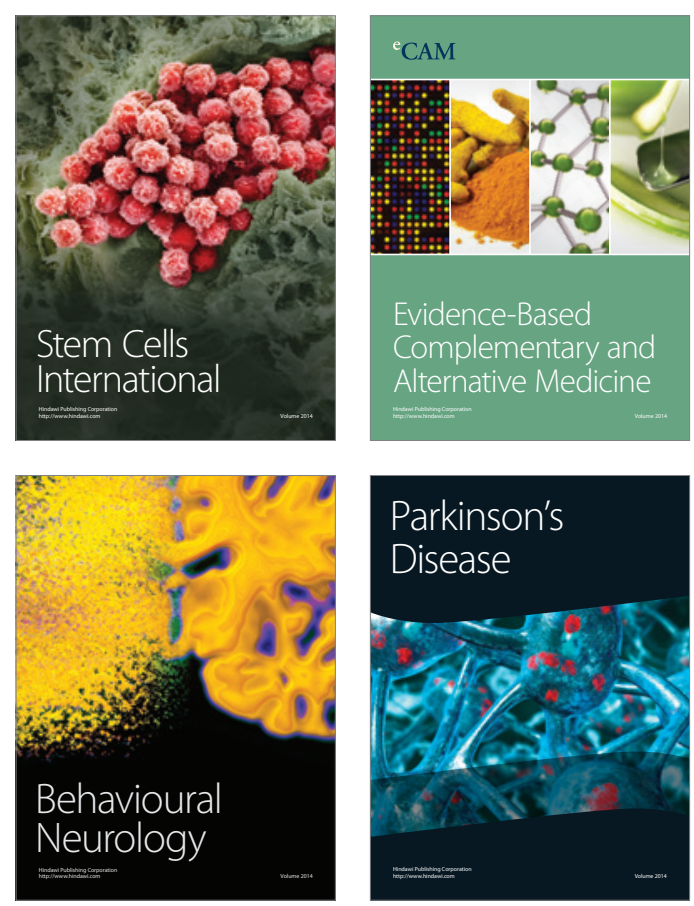

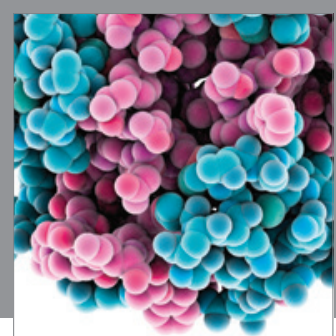

Journal of
Diabetes Research

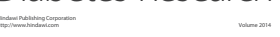

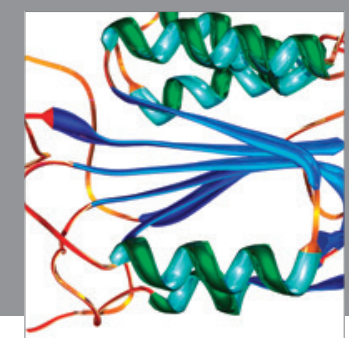

Disease Markers
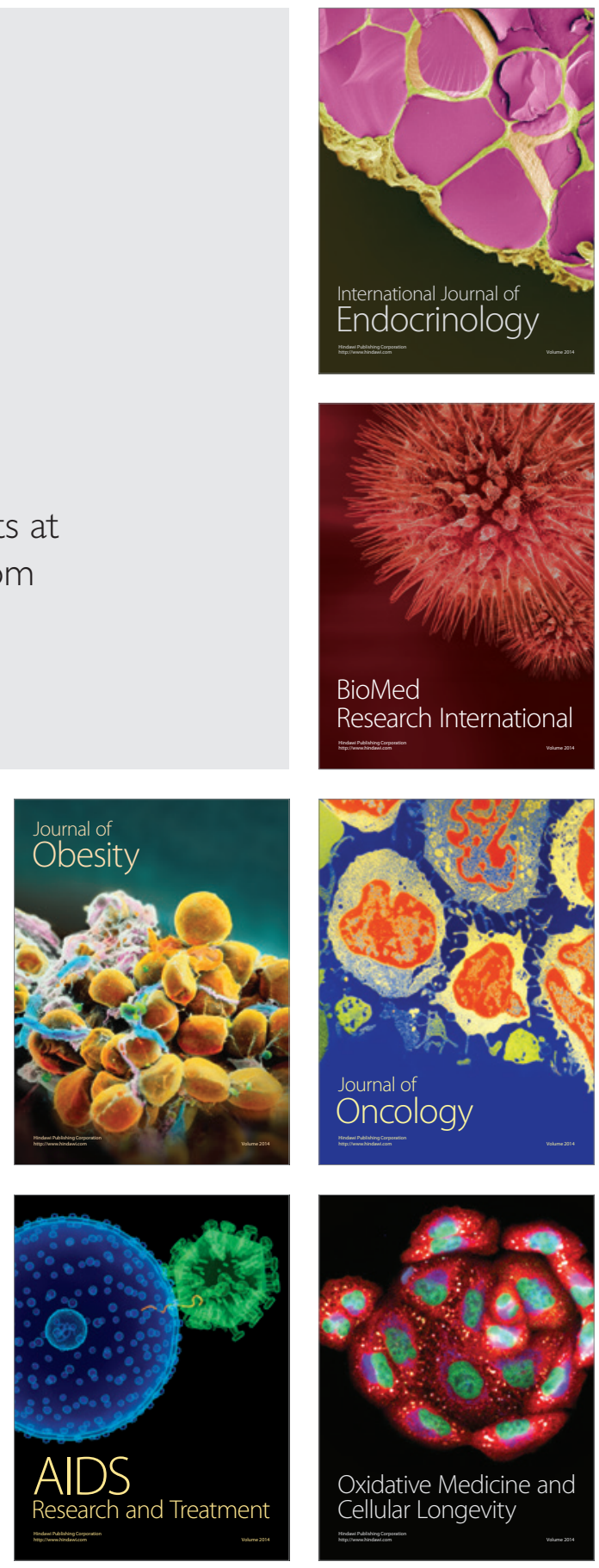